\title{
Assessing and Forecasting Saline Intrusion in the Vietnamese Mekong Delta Under the Impact of Upstream flow and Sea Level Rise
}

\author{
Tran Xuan Hai ${ }^{1}$, Vu Van Nghi ${ }^{2}$, Vu Hoang Hung ${ }^{3}$, Do Ngoc Tuan ${ }^{1}$, Dang Thanh Lam ${ }^{4}$ and Can Thu Van ${ }^{5}$ \\ 1. Institute for Science and Technology Innovation, Ho Chi Minh City 700000, Vietnam \\ 2. University of Science, Vietnam National University, Ho Chi Minh City 700000, Vietnam \\ 3. Thuyloi University, Ha No 100000, Vietnam \\ 4. Southern Institute for Water Resources Planning, Ho Chi Minh City 700000, Vietnam \\ 5. Ho Chi Minh City University of Natural Resources and Environment, Ho Chi Minh City 700000, Vietnam
}

\begin{abstract}
Saline intrusion is a hot issue and has always been of concern in the VMD (Vietnamese Mekong Delta), especially in the context of many changes of impact factors such as upstream flows and SLR (Sea Levels Rise). Vulnerability to changes in the upstream flows and SLR ismust-have reasons for updated and interpreted information. This information is used for exploiting of soil and water resources. MIKE 11 model was successfully applied to assess the saline intrusion. The study provided the picture of the saline intrusion in the dry season from January to May in the VMD in the existing situation (2015 and 2016) and the future (2030 and 2050 ) under the impact of flow at Kratie in various frequencies of $18 \%, 50 \%$ and $85 \%$ based on the time series of 2001-2016, and SLR according to RCP (Representative Concentration Pathway) 4.5 scenario of MONRE (Ministry of Natural Resources and Environment) of Vietnam issued in 2016. The results show that in the year 2015 the ASI (Saline Intrusion Area) in the VMD was relatively low due to moderate tidal level and high Kratie discharge $(P=18 \%)$. The scenario like the situation in 2016 and in the future ASI increased significantly compared to the 2015 baseline scenario which shows that the VMD is very vulnerable to saline intrusion. Based on multivariate regression analysis, the study also presented the formulas for the relationship between the ASI of $0.25 \mathrm{~g} / \mathrm{L}, 2.5 \mathrm{~g} / \mathrm{L}$ and $4.0 \mathrm{~g} / \mathrm{L}$ thresholds and the impact factors such as the average discharge at Kratie and the maximum daily tidal level in East Coast during the dry season from January to May. With an adjusted $R^{2}$ at $0.913-0.974$, these formulas are believed to be reliable for predicting ASIs based on the Kratie flow and the East Coast tidal level.
\end{abstract}

Key words: Saline intrusion, sea level rise, upstream flow, VMD.

\section{Introduction}

Saline intrusion is always a hot issue in the deltas where people exploit resources and live in concentration with high developing level. The saline intrusion in the estuaries and delta areas adjacent to the sea is a natural phenomenon and varieties are mainly depending on topographic conditions, tidal regimes and upstream flows $[1,2]$. In the context of climate change, rising sea levels, along with the exploitation of land and water resources of people in

Corresponding author: Can Thu Van, Ph.D., main researchfields: hydrology and waterresources. the basin, the saline intrusion into the deltas and estuaries has become more and more complicated. The current status and prediction of saline intrusion as well as building a quantitative relationship between the saline intrusion and the impact factors such as upstream flow and SLR (Sea Levels Rise) always need to be updated and interpreted for sustainable management of soil and water resources in the delta.

The VMD (Vietnamese Mekong Delta) is located at the end of the Mekong River system with an area about 3.9 million hectares. This is a rich agricultural land, playing a very important role in Vietnam's national food security and export strategy, specifically 


\section{Upstream flow and Sea Level Rise}

in 2018, shrimp production reached 0.62 million tons, pangasius 1.41 million tons, fruit 4.30 million tons, rice yield 24.50 million tons, equivalent to $70 \%, 95 \%$, $60 \%$ and $56 \%$ of the total national output respectively; and exports of key agricultural products accounted for $73.34 \%$ of the whole country [3]. However, the VMD is a flat lowland with dense river system and is influenced by the tides of the East Sea and the West Sea. The VMD is very vulnerable and always faced with saline intrusion disaster [4-6], especially during the dry season from January to May when the upstream flow is low. Recently, the saline intrusion had complicated with the fluctuations of upstream flows, climate change and SLR, it made more difficult for fresh water supply in the VMD. In the year 2016, the saline intrusion affected nine provinces in the VMD and caused great damage to almost economic sectors $[7,8]$.

The saline intrusion in the VMD under the impacts of upstream flows, climate change and SLR has been presented in previous studies [5, 6, 9-14]. They have indicated that the impacts of climate change, SLR and upstream flow changes increased the saline intrusion and negative impacts on water supply and agricultural products. However, the saline intrusion has been simulated in a part of VMD area and/or has not evaluated the factors affecting the saline intrusion. Khang, et al. [15] proposed the saline intrusion in the VMD under the impacts of SLR and upstream flow. However, the quantitative relationship between the saline intrusion and the impact factors such as SLR and upstream flow has not been determined. Tran, et al. [16] have only shown the relationship between the upstream flow change and the saline intrusion distance on some main rivers. On the other hand, the current upstream flow to the VMD has changed due to the regulation by dams in the upstream. The discharge during the dry season in the period from 2001 up to now at Kratie hydrological station is higher than in the past $[17,18]$. Hence, the impact of upstream flows on the saline intrusion in the VMD has separately analyzed the flow time series at Kratie in different stages. Moreover, the current SLR and climate change scenario were changed, the RCP4.5 scenario of MONRE (Ministry of Natural Resources and Environment) of Vietnam issued in 2016 [19] was applied for the VMD.

Many studies [12-15, 20, 21] successfully applied one-dimensional HD (Hydrodynamic) and AD (Advection-Dispersion) modelling in the VMD such as MIKE 11 [22]. Duong, et al. [23] have used MIKE 21 two-dimensional model [24, 25], and Tran Anh, et al. [26] have integrated one-dimensional modelling and two-dimensional modelling such as MIKE 11 and MIKE 21 to simulate the flow and saline intrusion on the Hau River, one river branch in the VMD. With a large area, dense river network and many hydraulic works, while existing input data and computational capacity are not available, hence one-dimensional modelling such as MIKE 11 has been considered feasible to apply to the flow and saline intrusion simulation for the entire Mekong Delta [26].

This study focused on simulation of saline intrusion in the dry season from January to May in the VMD according to the existing and forecasting scenarios to 2030 and 2050. The MIKE 11 was applied to assess the impact of changes in upstream flows and SLR. The changes of upstream flow are determined in various frequencies using the discharge time series at Kratie during the period from 2001 to 2016. The SLR was based on the RCP 4.5 scenario, whereby the SLR is predicted to increase $12 \mathrm{~cm}$ by 2030 and $22 \mathrm{~cm}$ by 2050 in comparison with the existing period. In addition, from the simulation results, and the relationship between the ASIs (saline intrusion areas) in the VMD and the upstream flow, the sea water level will be explained through multivariate regression analysis.

\section{Material and Methods}

The methodological framework in this study is described in Fig. 1. Firstly, the fully collected and 
processed input data and the MIKE 11 model were applied to simulate saline intrusion in the dry season from January to May according to the existing and future scenarios under the impact of changes of upstream flow at Kratie hydrological station and SLR to 2030 and 2050. Subsequently, the formula to quantify the factors affecting ASIs in the VMD was formulated through multivariate regression analysis.

The MIKE 11 model with NAM (Rainfall-Runoff), HD and ADmodules was used in this study. The MIKE 11 model was established in the range from Kratie hydrological station on the Mekong River and the Tonle Sap in Cambodia to the estuaries of the VMD and the lower Dong Nai River system in Vietnam (Fig. 2).
The hydraulic scheme consists of 988 tributaries with 7,189 cross-sections and 19,251 nodes, 147 major sluices to control saline intrusion in coastal zone of VMD and 120 water intakes.

In the hydraulic scheme, there are 8 upstream flow boundaries, 32 East Coast water level boundaries and 39 West Coast water level boundaries.

The specific model input data such as branches, and cross-sections and saline intrusion control structures are inherited from the data source of the SIWRP (Southern Institute for Water Resources Planning), the SIWRR (Southern Institute of Water Resources Research), and the BWE (Binh Minh Water \& Environment Company Limited), and the terrain data were updated from the sources of the Department of

DATA COLLECTION AND PROCESSING:

DEM $30 \times 30$ m, river network, cross-sections, sluices, intakes, meteo-hydrological time series in the period 2001-2016 (rainfall, evaporation, discharge, salt concentration, water level, tidal level)

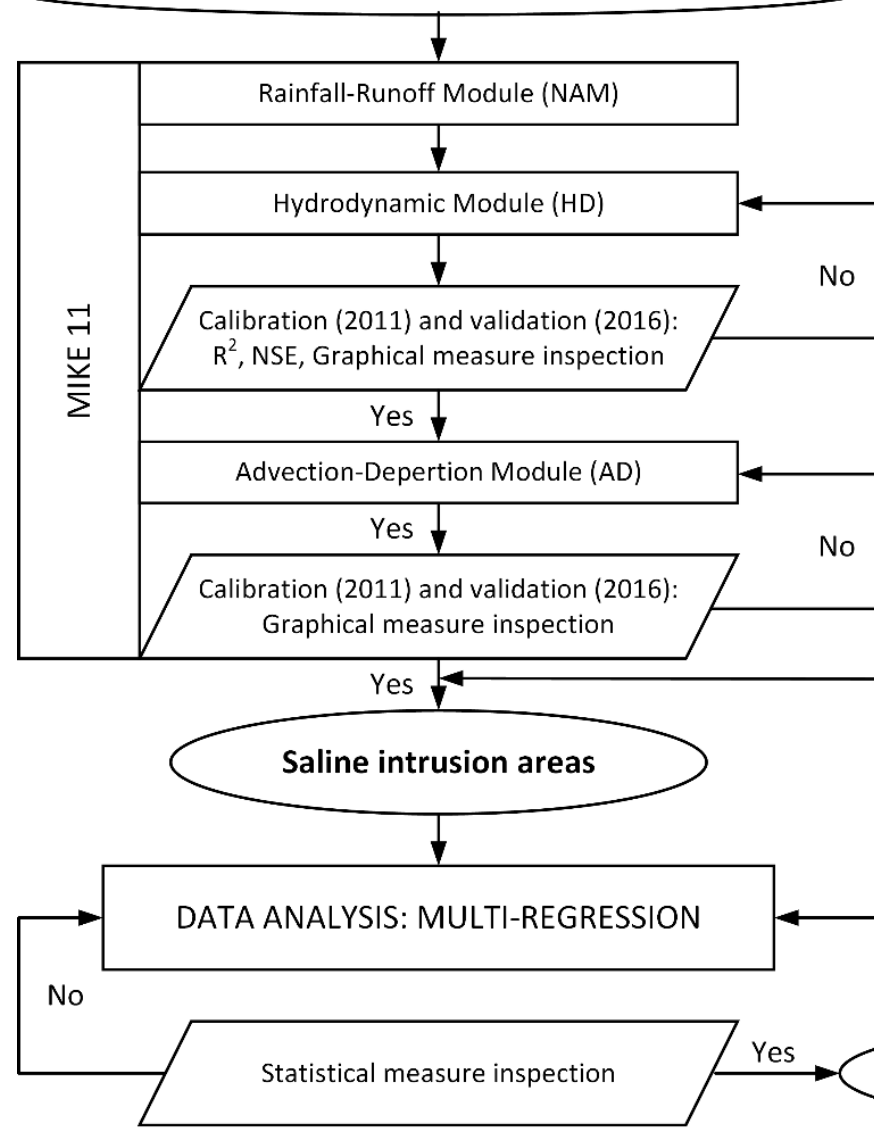

\section{SCENARIOS:}

- Scenario 1: 2015.

- Scenario 2: 2016.

- Scenario 3: 2030 - Tidal rise $12 \mathrm{~cm}$ \& Q Kratie in various probabilities

- Scenario 4: 2050 - Tidal rise $22 \mathrm{~cm}$ \& $Q$ Kratie in various probabilities

Fig. 1 Schematic framework of research methodology. 

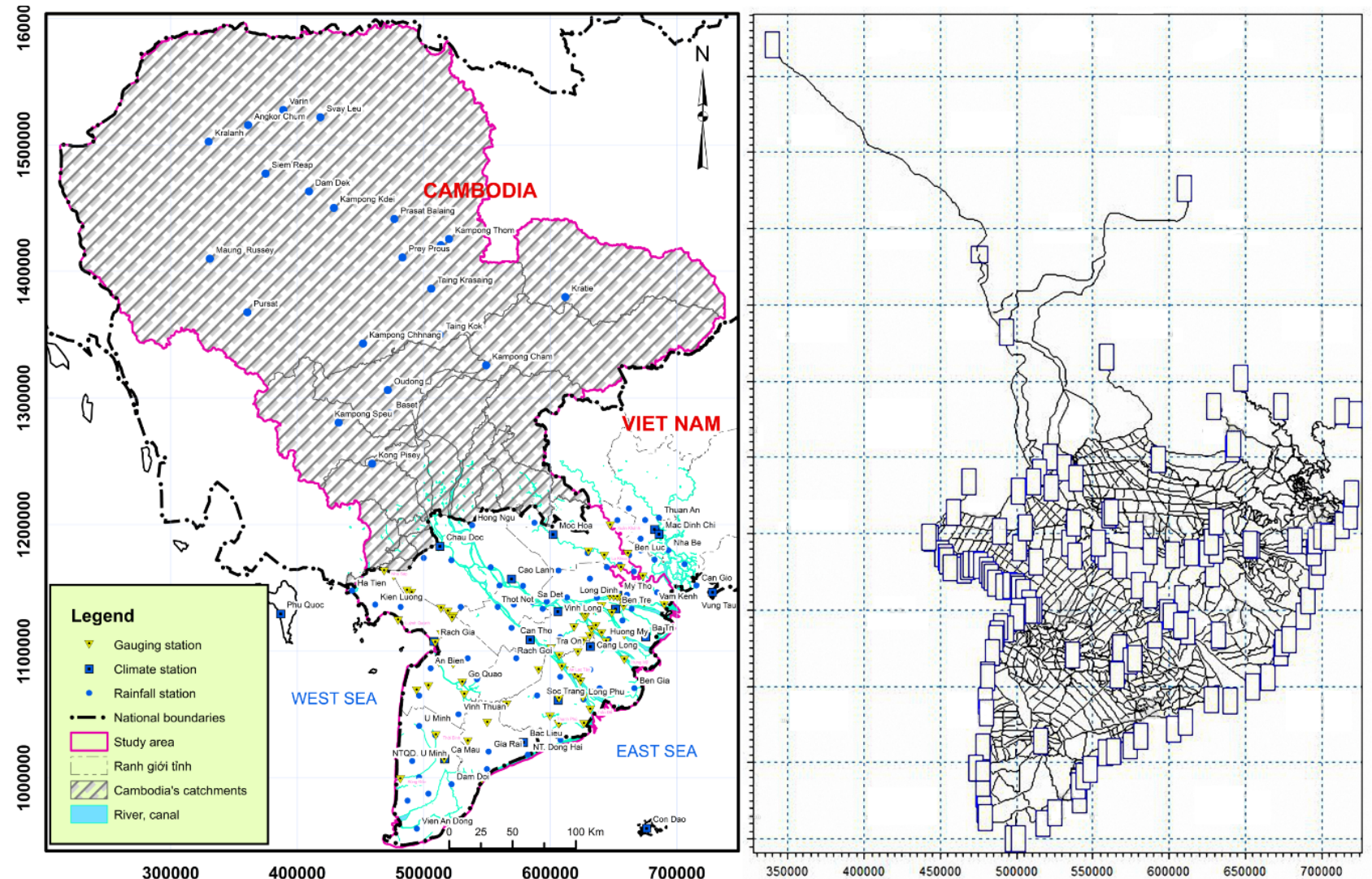

Fig. 2 Study area location and MIKE 11 scheme from Kratie and Tonle Sap (Cambodia) to river mouths (Vietnam).

Water Resources belonging to the provinces in the VMD. The DEM (Digital Elevation Model) $30 \mathrm{~m} \times 30$ $\mathrm{m}$ to delineate the sub-basins on the Cambodian side was downloaded from the U.S. Geological Survey [27]. The observed meteorological and hydrological data in the 2001-2016 period were collected from SIWRP, SIWRR, BWE and the Vietnam Meteorological and Hydrological Administration, including daily rainfall at 22 stations on Cambodia side. The set of NAM model parameters was referenced from the Dong Nai River basin which has similar conditions with the territory of Cambodia [28, 29].

To assess the saline intrusion during the dry season from January to May in the VMD, as well as for quantitative analysis between the ASI and impact factors such as upstream flows and sea level rise, four scenarios were built, including:

Scenario 1-Baseline scenario: The year 2015 was selected as the baseline scenario, in which the 2015 tide level is equivalent to the average tide level in the
2001-2016 period.

Scenario 2-Scenario of water scarcity in the existing period: Using the boundary conditions in the year 2016.

Scenario 3-Forecasting to 2030 under the impact: (1) Upstream flow changes at Kratie station wereconsidered in three cases of discharges such as: in the wet year 2015 with the frequency $P=18 \%$, the average year $P=50 \%$, and the dry year $P=85 \%$; (2) SLR under RCP4.5 scenario with an average value of $12 \mathrm{~cm}$ higher than the baseline scenario is shown in Figs. 3 and 4.

Scenario 4-Forecasting to 2050 under the impact: (1) Upstream flow changes at Kratie station were considered in three cases of discharges such as: in the wet year 2015 with the frequency $P=18 \%$, the average year $P=50 \%$, and the dry year $P=85 \%$; (2) SLR under RCP4.5 scenario with an average value of $22 \mathrm{~cm}$ higher than the baseline scenario is shown in Figs. 3 and 4. 


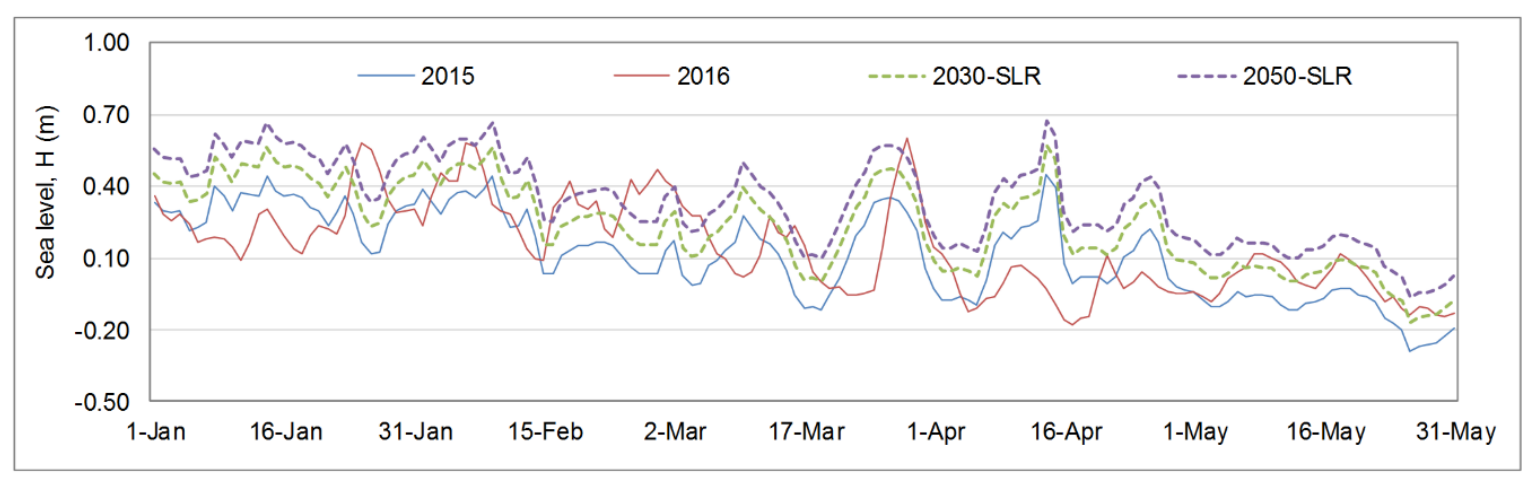

Fig. 3 An example of daily sea level at An Thuan station in various scenarios.

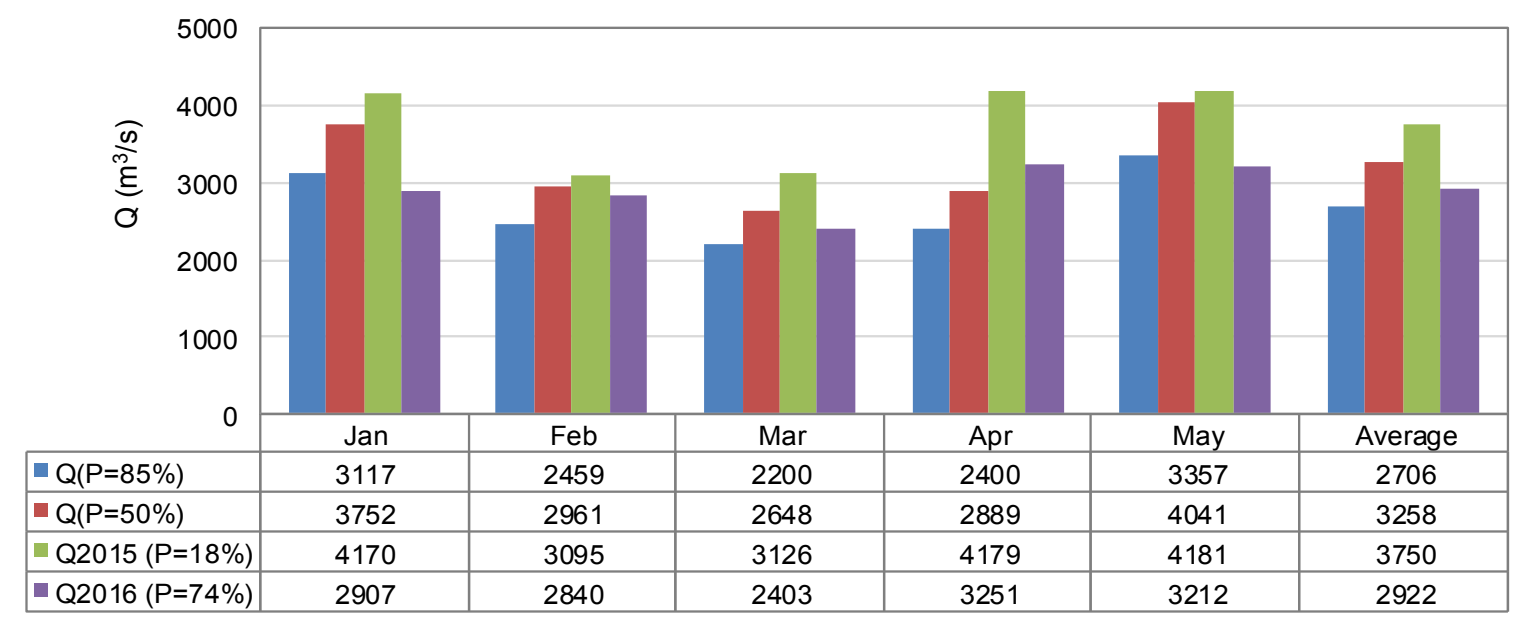

Fig. 4 Monthly observed discharge in the dry period from January to May at Kratie station.

\section{Results and Discussion}

\subsection{Calibration and Validation of the MIKE 11 Model}

The model was evaluated in two steps: (1) flow simulation; and (2) saline intrusion simulation. The model was calibrated during the dry season from January to May 2011, then validated during the period from January to May 2016.

HD model was calibrated through adjusting Manning coefficients, particularly Manning coefficient values ranging from 0.009 to 0.130 (mainly 0.03-0.04) for large rivers, and from 0.026 to 0.193 (mainly $0.045-0.055$ ) on small tributaries. The results of calibration and validation the flow simulation are shown in Table 1 in terms of Pearson correlation coefficient, $R^{2}$ and NSE coefficient [30] at the hydrological stations in the VMD as shown in Table 1. The water level and discharge calibration and validation at Tan Chau station on the Tien River and Chau Doc station on the Hau River are shown in Figs. 5 and 6.

The Pearson correlation coefficient $R^{2}$ ranges 0.928-0.995, and the NSE coefficient ranges 0.780-0.980 during the calibration and validation of hourly water levels and discharges at hydrological stations in the VMD. It indicated that the MIKE 11 HD model has been applied successfully to simulate flows in dry season in the VMD.

For saline intrusion simulation, the model is calibrated by adjusting diffusion coefficient $(D)$. The value of $D$ ranges $200-1,000 \mathrm{~m}^{2} / \mathrm{s}$ for large rivers and $20-300$ $\mathrm{m}^{2} / \mathrm{s}$ for small tributaries. The results of calibration and validation of saline intrusion are visually assessed through the graph of simulated salinity values and measured data at saline monitoring stations in the VMD during the dry season at the year 2011 and 2016 as indicated in Fig. 7; and comparison between the 

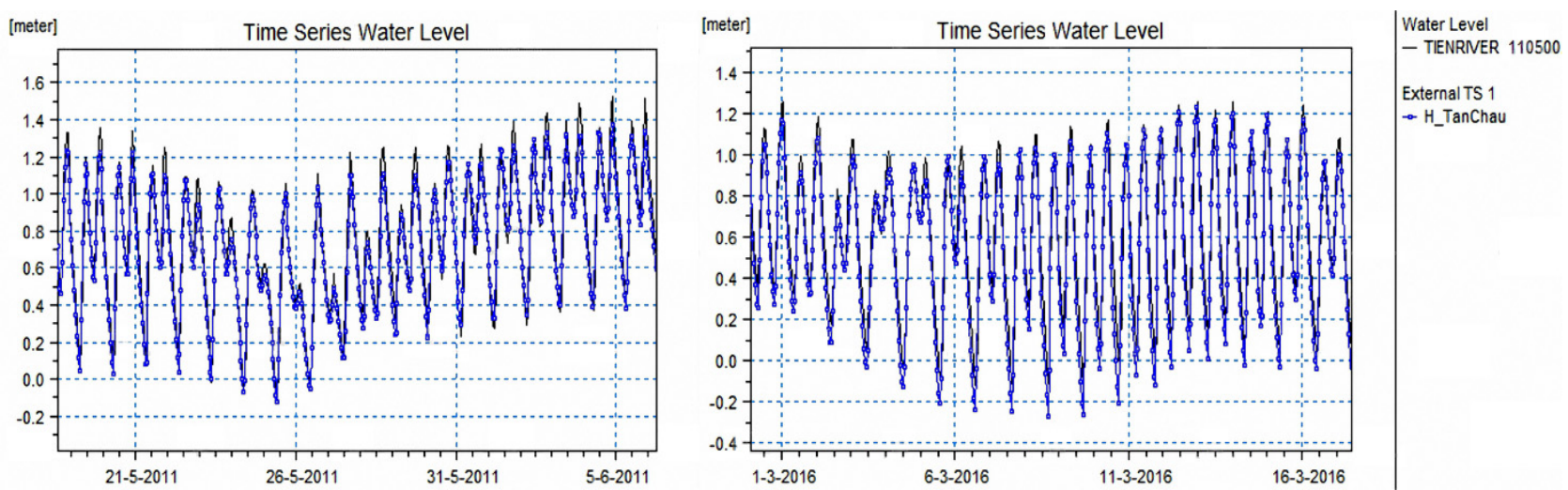

Fig. 5 Hourly simulated vs. observed water levels during the calibration (2011) and validation (2016) periods at Tan Chau station on the Tien River.
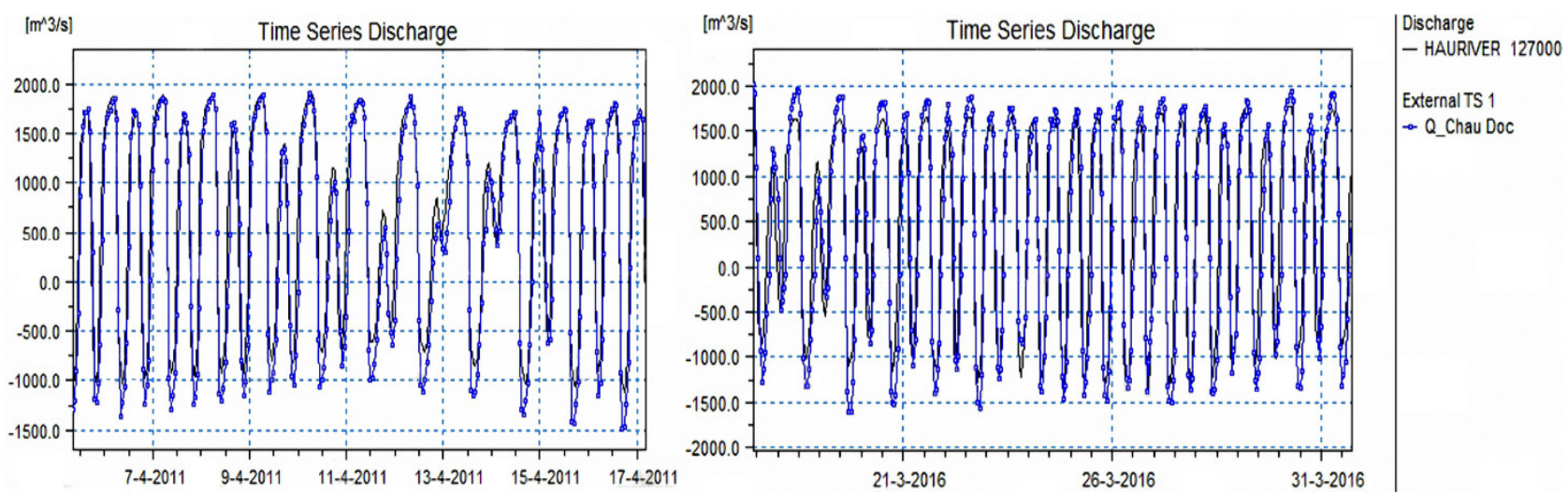

Fig. 6 Hourly simulated vs. observed discharges during the calibration (2011) and validation (2016) periods at Chau Doc station on the Hau River.

Table 1 MIKE 11 HD module performance in terms of Pearson correlation $\left(R^{2}\right)$ and NSE (Nash-Sutcliffe Efficient) coefficient at hydrological stations in the VMD in the calibration (2011) and validation (2016) periods.

\begin{tabular}{|c|c|c|c|c|c|c|c|c|c|}
\hline \multirow{3}{*}{ No. } & \multirow{3}{*}{ Gauging station } & \multicolumn{4}{|c|}{ Water level } & \multicolumn{4}{|c|}{ Discharge } \\
\hline & & \multicolumn{2}{|c|}{ Calibration } & \multicolumn{2}{|c|}{ Validation } & \multicolumn{2}{|c|}{ Calibration } & \multicolumn{2}{|c|}{ Validation } \\
\hline & & $\overline{R^{2}}$ & NSE & $R^{2}$ & NSE & $R^{2}$ & NSE & $R^{2}$ & NSE \\
\hline 1 & Tan Chau & 0.928 & 0.780 & 0.980 & 0.943 & 0.967 & 0.915 & 0.976 & 0.944 \\
\hline 2 & Chau Doc & 0.971 & 0.878 & 0.975 & 0.867 & 0.935 & 0.873 & 0.947 & 0.890 \\
\hline 3 & Long Xuyen & 0.989 & 0.705 & - & - & - & - & - & - \\
\hline 4 & Vam Nao & 0.989 & 0.943 & 0.984 & 0.916 & 0.933 & 0.858 & 0.957 & 0.883 \\
\hline 5 & Cao Lanh & - & - & 0.984 & 0.941 & - & - & - & - \\
\hline 6 & Can Tho & 0.967 & 0.935 & 0.983 & 0.965 & 0.966 & 0.925 & 0.971 & 0.941 \\
\hline 7 & Phung Hiep & 0.974 & 0.963 & 0.960 & 0.920 & - & - & - & - \\
\hline 8 & Dai Ngai & 0.987 & 0.969 & 0.987 & 0.968 & - & - & - & - \\
\hline 9 & My Thuan & 0.993 & 0.972 & 0.993 & 0.962 & 0.952 & 0.898 & 0.964 & 0.927 \\
\hline 10 & Tra Vinh & - & - & 0.995 & 0.968 & - & - & - & - \\
\hline 11 & Cho Lach & - & - & 0.995 & 0.846 & - & - & - & - \\
\hline 12 & My Tho & 0.990 & 0.980 & 0.954 & 0.905 & - & - & - & - \\
\hline 13 & Ben Luc & - & - & 0.941 & 0.880 & - & - & - & - \\
\hline 14 & Tan An & 0.958 & 0.901 & 0.969 & 0.856 & - & - & - & - \\
\hline
\end{tabular}

“-”No data available. 

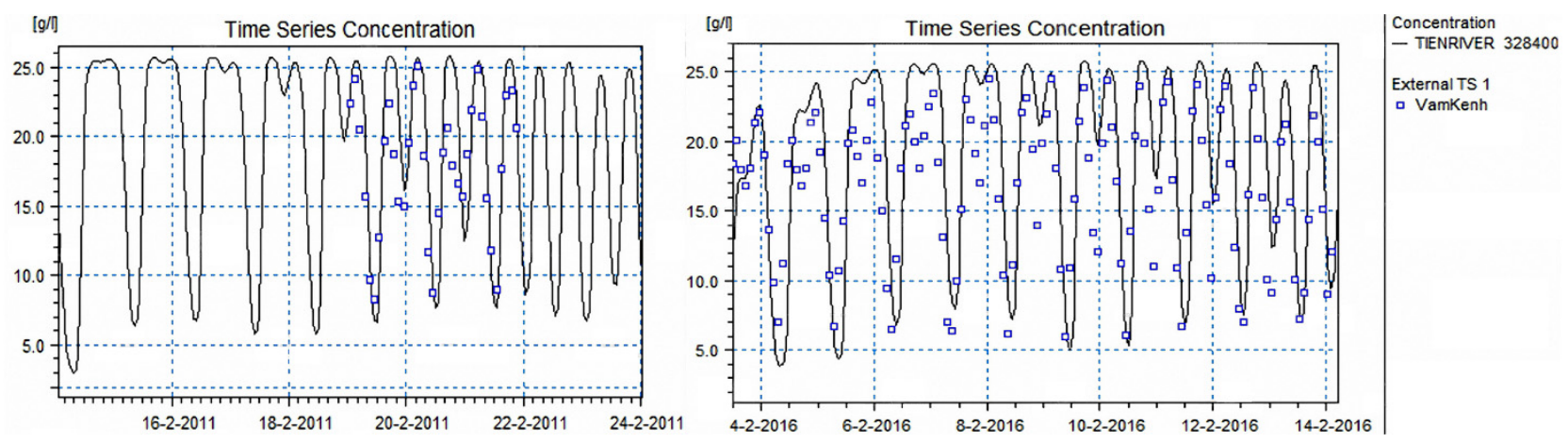

Fig. 7 Simulated vs. observed salinity concentration during the calibration (2011) and validation (2016) periods at Vam Kenh station on the Tien River.

Table 2 Comparison between simulated and observed distance from the river mouth to the saline boundaries of $1.0 \mathrm{~g} / \mathrm{L}, 2.0$ $\mathrm{g} / \mathrm{L}$ and $4.0 \mathrm{~g} / \mathrm{L}$ on some main rivers during the validation (2016) period.

\begin{tabular}{llllllllll}
\hline \multirow{2}{*}{ River Branch } & \multicolumn{3}{c}{ Saline boundary } & $1.0 \mathrm{~g} / \mathrm{L}$ & \multicolumn{3}{c}{ Saline boundary $2.0 \mathrm{~g} / \mathrm{L}$} & \multicolumn{3}{c}{ Saline boundary $4.0 \mathrm{~g} / \mathrm{L}$} \\
\cline { 2 - 10 } & $\begin{array}{l}\text { Sim. } \\
(\mathrm{km})\end{array}$ & $\begin{array}{l}\text { Obs. }^{2} \\
(\mathrm{~km})\end{array}$ & $\begin{array}{l}\text { Error }^{3} \\
(\%)\end{array}$ & $\begin{array}{l}\text { Sim. }^{1} \\
(\mathrm{~km})\end{array}$ & $\begin{array}{l}\text { Obs. }^{2} \\
(\mathrm{~km})\end{array}$ & $\begin{array}{l}\text { Error }^{3} \\
(\%)\end{array}$ & $\begin{array}{l}\text { Sim. }^{1} \\
(\mathrm{~km})\end{array}$ & $\begin{array}{l}\text { Obs. }^{2} \\
(\mathrm{~km})\end{array}$ & $\begin{array}{l}\text { Error }^{3} \\
(\%)\end{array}$ \\
\hline Vam Co Dong & 137 & 135 & $1 \%$ & 130 & 130 & $0 \%$ & 114 & 115 & $-1 \%$ \\
Vam Co Tay & 158 & 155 & $2 \%$ & 147 & 145 & $1 \%$ & 130 & 130 & $0 \%$ \\
Ham Luong & 86 & 90 & $-4 \%$ & 79 & 80 & $-1 \%$ & 72 & 73 & $-1 \%$ \\
Co Chien & 75 & 80 & $-6 \%$ & 69 & 75 & $-8 \%$ & 62 & 65 & $-5 \%$ \\
Hau & 73 & 70 & $4 \%$ & 70 & 67 & $4 \%$ & 60 & 60 & $0 \%$ \\
Cai Lon & 74 & 71 & $4 \%$ & 69 & 70 & $-1 \%$ & 63 & 68 & $-7 \%$ \\
\hline
\end{tabular}

${ }^{1}$ Simulated value; ${ }^{2}$ Observed value; and ${ }^{3}$ Error $=100 \times($ simulated value - observed value $) /$ observed value.

simulated maximum saline boundary with the survey data of the SIWRP during the dry season 2016 as shown in Table 2.

Table 2 and Fig. 7 showed the agreement between the simulated salinity concentration values and the monitored data. Salinity values that differ from simulation and measured at locations mouth to the saline boundary of $1.0 \mathrm{~g} / \mathrm{L}, 2.0 \mathrm{~g} / \mathrm{L}$ and $4.0 \mathrm{~g} / \mathrm{L}$ on the main stream showed: there are 15 cases $\leq 5 \%$ and only 3 cases from $6 \%-8 \%$ in total 18 observations.

\subsection{Assessing Saline Intrusion according to Scenarios and Factors Affecting}

The salinity thresholds of interest include: (1) salinity concentration of $0.25 \mathrm{~g} / \mathrm{L}$ - the standard salinity threshold for domestic water [31]; (2) salinity concentration of $2.5 \mathrm{~g} / \mathrm{L}$ - the standard salinity threshold for agriculture [32-34]; and (3) salinity concentration of $4.0 \mathrm{~g} / \mathrm{L}$ - the salinity threshold for the crop yield affected by salinity [32-34]. The simulation results of saline intrusion during the dry season from January to May according to the various scenarios are shown in Table 3 and Fig. 8.

For the baseline scenario (2015), the ASI of 0.25 $\mathrm{g} / \mathrm{L}, 2.5 \mathrm{~g} / \mathrm{L}$ and $4.0 \mathrm{~g} / \mathrm{L}$ covered $2.1676 \times 10^{10}$ ha, $1.6767 \times 10^{10}$ ha and $1.5549 \times 10^{10}$ ha (Table 3), equivalent to $56 \%, 43 \%$ and $40 \%$ of the total VMD area, respectively. This is a year with relatively low saline intrusion because the tidal level is at an average in the existing period of 2001-2016 and the upstream flow to the VMD is large (Figs. 3 and 4), namely, from January to May the average discharge at Kratie is $3,750 \mathrm{~m}^{3} / \mathrm{s}$ (corresponding to the frequency of $18 \%$ according to the standard distribution of flow data measured from 2001-2016).

For the year 2016 (Scenario 2) and the future to 2030 and 2050 under the impact of changes in upstream flow and SLR (Scenarios 3 and 4), the saline boundaries are much higher than the 2015 baseline scenario (Table 3 and Fig. 8). The main impacts of the 


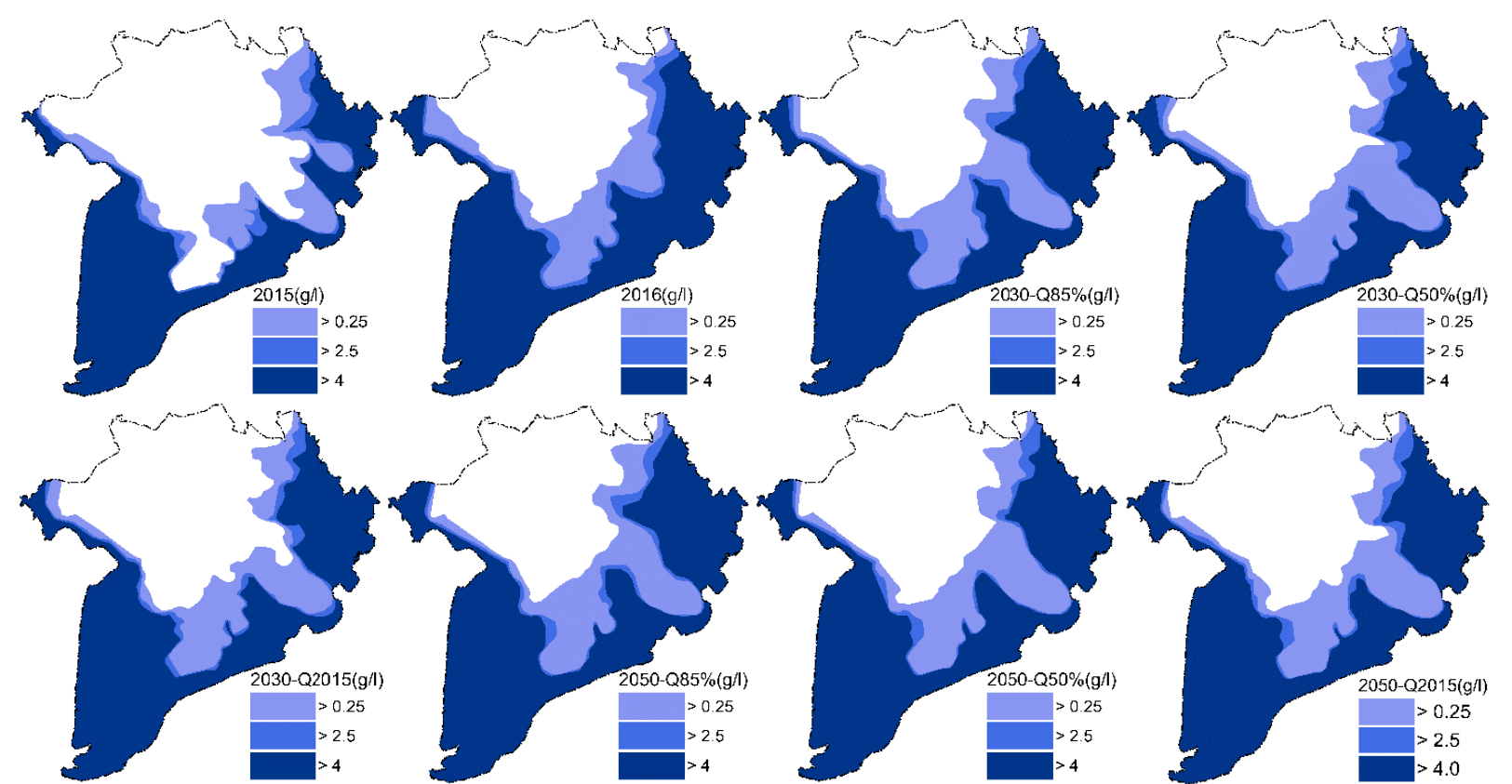

Fig. 8 Maps of the simulated ASI with the boundaries of $0.25 \mathrm{~g} / \mathrm{L}, 2.5 \mathrm{~g} / \mathrm{L}$ and $4.0 \mathrm{~g} / \mathrm{L}$ in the VMD under the various scenarios.

Table 3 Simulated ASIs with boundaries of $0.25 \mathrm{~g} / \mathrm{L}, 2.5 \mathrm{~g} / \mathrm{L}$ and $4.0 \mathrm{~g} / \mathrm{L}$ in the VMD under the various scenarios.

\begin{tabular}{|c|c|c|c|c|c|c|}
\hline \multirow{3}{*}{ Scenario } & \multicolumn{6}{|c|}{ Simulated ASI in various boundaries } \\
\hline & \multicolumn{2}{|c|}{$0.25 \mathrm{~g} / \mathrm{L}$} & \multicolumn{2}{|c|}{$2.5 \mathrm{~g} / \mathrm{L}$} & \multicolumn{2}{|c|}{$4.0 \mathrm{~g} / \mathrm{L}$} \\
\hline & $\begin{array}{l}\text { Area } \\
\left(10^{6} \mathrm{ha}\right)\end{array}$ & $\begin{array}{l}\text { Increasing }^{1} \\
(\%)\end{array}$ & $\begin{array}{l}\text { Area } \\
\left(10^{6} \mathrm{ha}\right)\end{array}$ & $\begin{array}{l}\text { Increasing }{ }^{1} \\
(\%)\end{array}$ & $\begin{array}{l}\text { Area } \\
\left(10^{6} \mathrm{ha}\right)\end{array}$ & $\begin{array}{l}\text { Increasing }{ }^{1} \\
(\%)\end{array}$ \\
\hline 2015 (Baseline) & 21,676 & - & 16,767 & - & 15,549 & - \\
\hline 2016 & 25,405 & $17 \%$ & 18,618 & $11 \%$ & 17,603 & $13 \%$ \\
\hline 2030 (Q2015) & 23,939 & $10 \%$ & 17,495 & $4 \%$ & 16,479 & $6 \%$ \\
\hline $2030(\mathrm{Q} 50 \%)$ & 24,827 & $15 \%$ & 18,084 & $8 \%$ & 17,142 & $10 \%$ \\
\hline $2030(\mathrm{Q} 85 \%)$ & 26,101 & $20 \%$ & 19,037 & $14 \%$ & 17,973 & $16 \%$ \\
\hline $2050(\mathrm{Q} 2015)$ & 24,823 & $15 \%$ & 17,972 & $7 \%$ & 17,055 & $10 \%$ \\
\hline $2050(\mathrm{Q} 50 \%)$ & 25,255 & $17 \%$ & 18,426 & $10 \%$ & 17,392 & $12 \%$ \\
\hline $2050(\mathrm{Q} 85 \%)$ & 26,527 & $22 \%$ & 19,555 & $17 \%$ & 18,364 & $18 \%$ \\
\hline
\end{tabular}

${ }^{1}$ The values increase compared to the 2015 baseline scenario.

changes are: (1) tides and (2) upstream flows to the VMD. With tides, the VMD has been influenced by the tidal regime of the East Sea and the West Sea. The East Sea tide is a semi-tide with large amplitude (3.5-4.0 m), monthly the tide appears two spring tides and two neap tides, the maximum difference between the two tide periods is about $1.5-2.0 \mathrm{~m}$. The West Sea tide is a irregular diurnal tide with small amplitude, usually the tide level is from 0.2 to $0.4 \mathrm{~m}$, the tidal peak is from 0.6 to $0.8 \mathrm{~m}$, and the largest amplitude is about 0.8-1.2 m. Based on the tidal characteristics, the saline intrusion in the VMD is mainly influenced by the East Sea tide. In addition, the West coast from Rach Gia to Ha Tien has anti-saline constructions, so the boundary of saline intrusion in this area has not changed much. With upstream flow, the flow into the VMD consists of two main sources, namely the Kratie flow on the Mekong River; and the contribution flow from Tonle Sap through the Hau River. The Tonle Sap with a mean storage volume of 49 billion $\mathrm{m}^{3}$ that has affected the regulationof the flow for the VMD from Phnom Penh, thus the flow in dry months has been 
increased. However, according to Toan [18], on average in March and April the contribution rate of flows to the VMD is about $26.5 \%$, with drought year about $20.5 \%$. Thus, the fluctuation of flow in Kratie plays a major role in the change of saline intrusion in the VMD.

From the point of view of the two main impact factors such as the flow at Kratie and the tidal level in the East Sea, the simulation is shown in Table 3 indicating the effects of their fluctuations on the ASIs in the VMD. With the effect of tidal fluctuations in the East Sea on the saline intrusion and high upstream flow (e.g. particularly the average dry season discharge at Kratie $Q_{\text {dry }}=3,750 \mathrm{~m}^{3} / \mathrm{s}$ ), the SLR of $1.5 \mathrm{~cm}, 3.1$ $\mathrm{cm}$ and $2.2 \mathrm{~cm}$ then the ASI of $0.25 \mathrm{~g} / \mathrm{L}, 2.5 \mathrm{~g} / \mathrm{L}$ and $4.0 \mathrm{~g} / \mathrm{L}$ will be increased $1 \%$. With moderate upstream flow $\left(Q_{\text {dry }}=3,258 \mathrm{~m}^{3} / \mathrm{s}\right)$ and the SLR increases $1.1 \mathrm{~cm}$, $1.8 \mathrm{~cm}$ and $1.5 \mathrm{~cm}$ then the ASI of $0.25 \mathrm{~g} / \mathrm{L}, 2.5 \mathrm{~g} / \mathrm{L}$ and $4.0 \mathrm{~g} / \mathrm{L}$ will be increased $1 \%$. With low upstream flow $\left(Q_{\text {dry }}=2,706 \mathrm{~m}^{3} / \mathrm{s}\right)$ and upto the year 2030 the SLR will be increased $0.6-0.7 \mathrm{~cm}$ then the ASI will be increased $1 \%$, while in the $2030-2050$ period the SLR will be increased $10 \mathrm{~cm}$ then the ASI of $0.25 \mathrm{~g} / \mathrm{L}, 2.5$ $\mathrm{g} / \mathrm{L}$ and $4.0 \mathrm{~g} / \mathrm{L}$ will be increased $2.5 \%$.

With the effects of upstream flow fluctuations on saline intrusion and the low SLR $(0-12 \mathrm{~cm})$, the flow at Kratie will be decreased about $105-110 \mathrm{~m}^{3} / \mathrm{s}$ then the ASI of $0.25 \mathrm{~g} / \mathrm{L}, 2.5 \mathrm{~g} / \mathrm{L}$ and $4.0 \mathrm{~g} / \mathrm{L}$ will be increased $1 \%$. When the SLR increases $12-22 \mathrm{~cm}$ and the dry season flow at Kratie is high $(P<50 \%)$ then the discharge will be decreased $200 \mathrm{~m}^{3} / \mathrm{s}$ so that the
ASI of $0.25 \mathrm{~g} / \mathrm{L}, 2.5 \mathrm{~g} / \mathrm{L}$ and $4.0 \mathrm{~g} / \mathrm{L}$ will be increased $1 \%$. In case the SLR is from $12-22 \mathrm{~cm}$ and the dry season flow at Kratie is low $(P>50 \%)$, the discharge will be decreased $100 \mathrm{~m}^{3} / \mathrm{s}$ then the ASI of $0.25 \mathrm{~g} / \mathrm{L}$, $2.5 \mathrm{~g} / \mathrm{L}$ and $4.0 \mathrm{~g} / \mathrm{L}$ will be increased $1 \%$.

\subsection{The Relationship between ASIs and Kratie Flow, East Sea Tidal Water Levels}

For ease of quantitative analysis of the relationship between the ASI in the VMD and the effects of the upstream flow and the tidal level, the method of multivariate regression was applied. The results of multivariate regression analysis have formulated the relationship between the ASI with the boundary of $0.25 \mathrm{~g} / \mathrm{L}, \operatorname{ASI}_{0.25 \mathrm{~g} / \mathrm{L}}\left(10^{6} \mathrm{ha}\right) ; 2.5 \mathrm{~g} / \mathrm{L}, \operatorname{ASI}_{2.5 \mathrm{~g} / \mathrm{L}}\left(10^{6} \mathrm{ha}\right)$; and $4.0 \mathrm{~g} / \mathrm{L}, \operatorname{ASI}_{4.0 \mathrm{~g} / \mathrm{L}}\left(10^{6} \mathrm{ha}\right)$ and the impact factors such as the maximum daily tide level in the East Coast, $H_{\text {day,max }}(\mathrm{m})$ and the average discharge at Kratie, $Q_{\text {dry,mean }}\left(\mathrm{m}^{3} / \mathrm{s}\right)$, during the dry season from January to May as shown in Eqs. (1)-(3) and Fig. 9.

$$
\begin{aligned}
& \mathrm{ASI}_{\frac{0.25 \mathrm{~g}}{\mathrm{~L}}}=11,415 H_{\text {day,max }}-2.05 Q_{\text {dry,mean }} \\
& +24,680 \\
& \mathrm{ASI}_{2.5 \mathrm{~g} / \mathrm{L}}=4,988 H_{\text {day,max }}-1.48 Q_{\text {dry,mean }} \\
& +20,088 \\
& \mathrm{ASI}_{4.0 \mathrm{~g} / \mathrm{L}}=5,703 H_{\text {day,max }}-1.39 Q_{\text {dry,mean }} \\
& +18,322
\end{aligned}
$$

In terms of statistical criteria, specifically the adjusted $R^{2}$ equals 0.913 for $\mathrm{ASI}_{0.25 \mathrm{~g} / \mathrm{L}}$ (as illustrated in Fig. 9a), 0.974 for $\mathrm{ASI}_{2.5 g / \mathrm{L}}$ (Fig. 9b) and 0.965 for $\mathrm{ASI}_{4.0 \mathrm{~g} / \mathrm{L}}$ (Fig. 9c), the multivariate regression model is
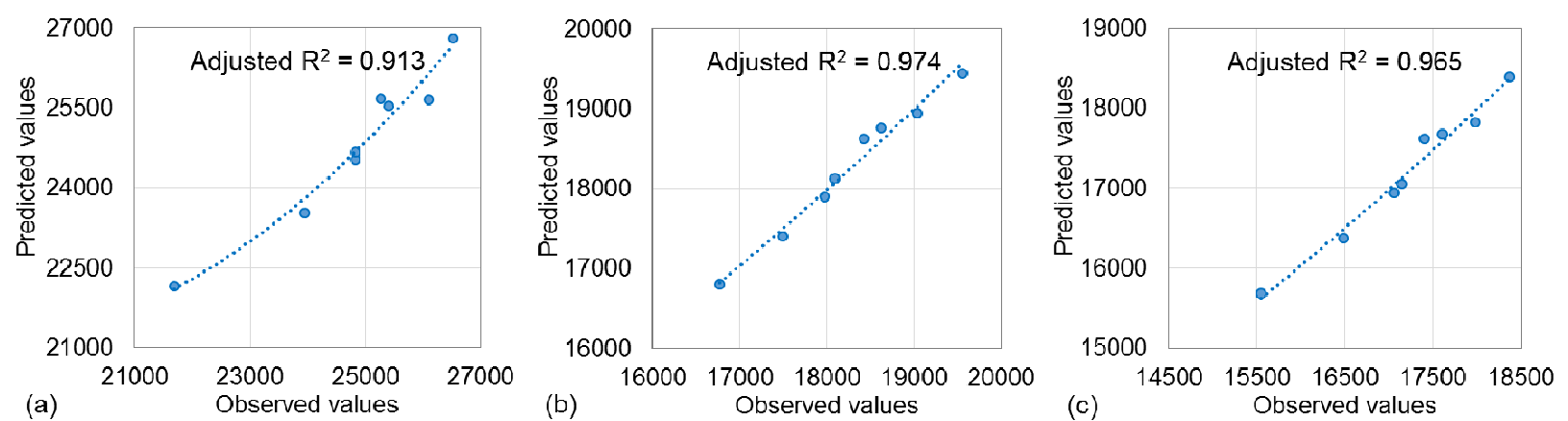

Fig. 9 Illustration of the regression analysis result of the relationship between ASI in the VMD and the changes of maximum daily tide level in the East Coast and average discharge at Kratie during the dry season: (a) ASI of 0.25 g/L, (b) ASI of $2.5 \mathrm{~g} / \mathrm{L}$, and (c) ASI of $4.0 \mathrm{~g} / \mathrm{L}$. 
considered to be reliable. Furthermore, this very strong level of correlation reinforces the perception that without major human intervention altering the topography of the VMD (e.g. dykes, saline control sluices), the upstream flows at Kratie and the East Sea tidal level are the main factors governing saline intrusion in the VMD. Therefore, Eqs. (1)-(3) can be used to quickly predict the ASI with the boundary of $0.25 \mathrm{~g} / \mathrm{L}, 2.5 \mathrm{~g} / \mathrm{L}$ and $4 / 0 \mathrm{~g} / \mathrm{L}$ under the impact of upstream flows and SLR during the dry season from January to May in the VMD.

\section{Conclusions}

This paper presents an assessing existing and future saline intrusion in the VMD under the impact of upstream flows and SLR by integrating the MIKE 11 model with the modules such as NAM, HD and AD, and also the method of multivariate regression analysis. The performance of the MIKE 11 model was evaluated using historical data in the dry season January to May at the hydrological and saline monitoring stations. Overall, the performance of the MIKE 11 model was excellent in estimating stream flow as demonstrated by the statistical measures including Pearson correlation coefficient $R^{2}$ having a range of 0.928-0.995 and NSE coefficient at $0.780-0.980$ during the calibration and validation. It indicated that the MIKE 11 HD model has successfully simulated water level and discharge in dry season in the VMD. The MIKE 11 model was also excellent in estimating saline intrusion. The study has also provided a picture of the saline intrusion in the dry season from January to May in the VMD in the years 2015, 2016 and the future (2030 and 2050) under the impact of changes of upstream flow and SLR. The results showed that in 2015, the saline area in the VMD was relatively low. The scenario like the situation in 2016 and in the future ASI increased significantly compared to the 2015 baseline scenario. It can be concluded that the VMD is very vulnerable to saline intrusion in which two main governing factors have been clarified, namely the flow at Kratie hydrological station and the East Sea tidal level. From the simulation result of saline intrusion, the observed time series in the 2001-2016 period, and based on the method of multivariate regression analysis, the study also presented the formulas for the relationship between the ASI with the boundary of $0.25 \mathrm{~g} / \mathrm{L}$, $\operatorname{ASI}_{0.25 \mathrm{~g} / \mathrm{L}}\left(10^{6} \mathrm{ha}\right)$, and $2.5 \mathrm{~g} / \mathrm{L}, \mathrm{ASI}_{2.5 \mathrm{~g} / \mathrm{L}}\left(10^{6} \mathrm{ha}\right)$ and $4.0 \mathrm{~g} / \mathrm{L}, \mathrm{ASI}_{4.0 \mathrm{~g} / \mathrm{L}}\left(10^{6} \mathrm{ha}\right)$ and the impact factors such as the maximum daily tidal level in the East Coast, $H_{\text {day,max }}(\mathrm{m})$ and the average discharge at Kratie, $Q_{\text {dry,mean }}\left(\mathrm{m}^{3} / \mathrm{s}\right)$ during the dry season from January to May. With the adjusted $R^{2}$ at $0.913-0.974$, these formulas are believed to be reliable for predicting ASIs based on Kratie flow and East Coast tidal levels to support decision makers.

\section{Acknowledgments}

This research was funded by the Program of Science and Technology in Response to Climate Change, Natural Resources and Environment Management in the Period 2016-2020, the Ministry of Natural Resources and Environment of Vietnam, grant number 11/HĐ-KHCN-BĐKH/16-20. Besides that, kind assistance with data collection and research process was supported by the SIWRP, the SIWRR and the BWE.

\section{References}

[1] Dyer, K. R., ed. 1997. Estuaries: A Physical Introduction. Chichester, New York: John Wiley.

[2] van Leussen, W., and Dronkers, J. 1988. "Physical Processes in Estuaries: An Introduction." In Physical Processes in Estuaries, Berlin, Heidelberg: Springer, 1-18.

[3] Directorate of Fisheries. 2019. "Sustainable Development of Agriculture in the Vietnamese Mekong Delta." https://tongcucthuysan.gov.vn/en-us/News/-Ngh\%E1\%B B $\% 81-\mathrm{c} \% \mathrm{C} 3 \% \mathrm{~A} 1$-trong-n $\% \mathrm{C} 6 \% \mathrm{~B} 0 \% \mathrm{E} 1 \% \mathrm{BB} \% 9 \mathrm{Bc} / \mathrm{doc}-$ tin/013088/2019-06-21/phat-trien-ben-vung-nganh-nongnghiep-tai-dong-bang-song-cuu-long.

[4] Hoan, N. X., Nguyen Khoi, D., and Trung, L. D. 2019. "Assessing the Adaptive Capacity of Farmers under the Impact of Saltwater Intrusion in the Vietnamese Mekong 
Delta." Journal of Environmental Planning and Management 62: 1619-35.

[5] Smajgl, A., Toan, T. Q., Nhan, D. K., Ward, J., Trung, N. H., Tri, L. Q., et al. 2015. "Responding to Rising Sea Levels in the Mekong Delta." Nature Climate Change 5: 167-74.

[6] Trieu, T. T. N., and Phong, N. T. 2015. "The Impact of Climate Change on Salinity Intrusion and Pangasius (Pangasianodon Hypophthalmus) Farming in the Mekong Delta, Vietnam." Aquaculture International 23: 523-34.

[7] Sebastian, L., Sander, B. O., Simelton, E., Zheng, S., Hoanh, C., Tran, N., et al. 2016. The Drought and Salinity Intrusion in the Mekong River Delta of Vietnam. Assessment report, CCAFS-SEA.

[8] Anh, N. N. 2016. What Is the Solution for 2016 Drought and Saltwater Intrusion in the Mekong Delta? Southern Institute for Water Resources Planning. (in Vietnamese)

[9] Dang, V. H., Tran, D. D., Pham, T. B. T., Khoi, D. N., Tran, P. H., and Nguyen, N. T. 2019. "Exploring Freshwater Regimes and Impact Factors in the Coastal Estuaries of the Vietnamese Mekong Delta." Water 11 (4): 782.

[10] Hoang, H. N., Huynh, H. X., and Nguyen, T. H. 2012. "Simulation of Salinity Intrusion in the Context of the Mekong Delta Region (Viet Nam)." In Proceedings of the 2012 IEEE RIVF International Conference on Computing \& Communication Technologies, Research, Innovation, and Vision for the Future, 1-4.

[11] Huu-Thoi, N., and Gupta, A. D. 2001. "Assessment of Water Resources and Salinity Intrusion in the Mekong Delta." Water International 26: 86-95.

[12] Thi Nhung, T., Le Vo, P., Van Nghi, V., and Quoc Bang, H. 2019. "Salt Intrusion Adaptation Measures for Sustainable Agricultural Development under Climate Change Effects: A Case of Ca Mau Peninsula, Vietnam." Climate Risk Management 23: 88-100.

[13] Thao, N. D., Takagi, H., and Esteban, M. 2014. Coastal Disasters and Climate Change in Vietnam. Boston: Elsevier.

[14] Vu, D. T., Yamada, T., and Ishidaira, H. 2018. "Assessing the Impact of Sea Level Rise due to Climate Change on Seawater Intrusion in Mekong Delta, Vietnam." Water Science and Technology 77: 1632-39.

[15] Khang, N. D., Kotera, A., Sakamoto, T., and Yokozawa, M. 2008. "Sensitivity of Salinity Intrusion to Sea Level Rise and River Flow Change in Vietnamese Mekong Delta-Impacts on Availability of Irrigation Water for Rice Cropping." Journal of Agricultural Meteorology 64: 167-76.

[16] Tran, D., Likitdecharote, K., Srisatit, T., and Trung, N. 2011. "Modeling the Influence of River Discharge and Sea Level Rise on Salinity Intrusion in Mekong Delta."
Presented at The 1st Environment Asia International Conference on Environmental Supporting in Food and Energy Security: Crisis and Opportunity, 22-25 March 2011, Bangkok, Thailand, 685-701.

[17] Pokhrel, Y., Burbano, M., Roush, J., Kang, H., Sridhar, V., and Hyndman, D. W. 2018. "A Review of the Integrated Effects of Changing Climate, Land Use, and Dams on Mekong River Hydrology." Water 10 (3): 266.

[18] Toan, T. Q. 2015. Studying Upstream Development Possibilities Affecting the Flow Regime and Saline Intrusion in the Dry Season in the Mekong Delta. Southern Institute of Water Resource Research, Vietnam. (in Vietnamese)

[19] MONRE (Ministry of Natural Resources \& Environment). 2016. Climate Change and Sea Level Rise Scenarios for Vietnam. Vietnam Publishing House of Natural Resources, Environment and Cartography. (in Vietnamese)

[20] Hanington, P., To, Q. T., Van, P. D. T., Doan, N. A. V., and Kiem, A. S. 2017. "A Hydrological Model for Interprovincial Water Resource Planning and Management: A Case Study in the Long Xuyen Quadrangle, Mekong Delta, Vietnam." Journal of Hydrology 547: 1-9.

[21] Mishra, P., Tri, D., Ching, C., and Don, N. C. 2014. "Modeling the Influence of River Flow and Salinity Intrusion in the Mekong River Estuary, Vietnam." Lowland Technology International 16: 14-26.

[22] DHI. 2014. MIKE 11-A Modelling System for Rivers and Channels: Reference Manual. Hørsholm, Denmark: Danish Hydraulic Institute.

[23] Duong, T. A., Bui, M. D., and Rutschmann, P. 2015. "Impact of Climate Change on Salinity Intrusion in the Mekong Delta." Presented at the 14th International Conference on Environmental Science and Technology (CEST2015), Rhodes, Greece.

[24] DHI. 2014. MIKE 21 Flow Model: Hydrodynamic Module, Scientific Documentation. Hørsholm, Denmark: Danish Hydraulic Institute.

[25] DHI. 2014. MIKE 21 Flow Model: Advection-Dispersion Module, Scientific Documentation. Hørsholm, Denmark: Danish Hydraulic Institute.

[26] Tran Anh, D., Hoang, L. P., Bui, M. D., and Rutschmann, P. 2018. "Simulating Future Flows and Salinity Intrusion Using Combined One- and Two-Dimensional Hydrodynamic Modelling-The Case of Hau River, Vietnamese Mekong Delta." Water 10: 897.

[27] USGS (United States Geological Survey). 2016. "Shuttle Radar Topography Mission Non-Void Filled." https://earthexplorer.usgs.gov/.

[28] Nghi, V. V., and Au, N. H. 2014. "Assessment of the Water Transfer Capacity from Be River Basin through 

Upstream flow and Sea Level Rise

Phuoc Hoa Hydraulic-Works." Clean Soil, Air, Water 43: 645-51.

[29] Nghi, V. V. 2016. Assessment of Water Scarcity for Ho Chi Minh City by Water Stress Index under the 2030 Planning Scenario in the Climate Change Conditions and General Solutions to Reduce. Final Report, University of Science, Viet Nam National University HCMC. (in Vietnamese)

[30] Nash, J. E., and Sutcliffe, J. V. 1970. "River Flow Forecasting through Conceptual Models Part I-A Discussion of Principles." Journal of Hydrology 10: 282-90.

[31] MONRE (Ministry of Natural Resources and
Environment: Ha Noi). 2015. National Technical Regulation on Surface Water Quality. Ha Noi, Viet Nam: MONRE. (in Vietnamese)

[32] Ayers, R. S., and Westcot, D. W. 1994. Water Quality for Agriculture. Food and Agriculture Organization of the United Nations.

[33] Rhoades, J. D., Kandiah, A., and Mashali, A. M. 1992. The Use of Saline Waters for Crop Production. Food and Agriculture Organization of the United Nations.

[34] Tanji, K. K., and Kielen, N. C. 2002. Agricultural Drainage Water Management in Arid and Semi-arid Areas. Food and Agriculture Organization of the United Nations. 